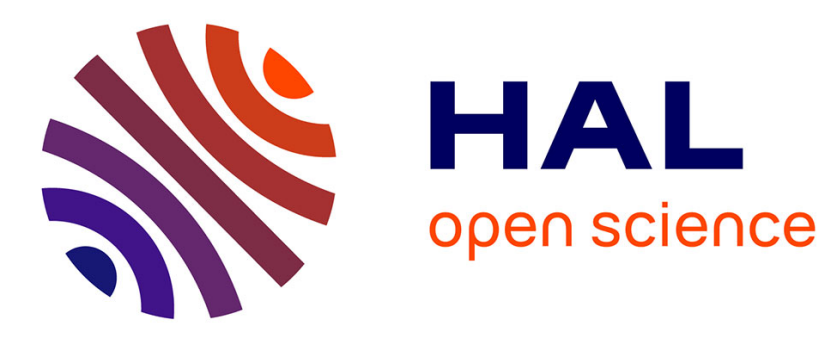

\title{
Pooled warehouse management: An empirical study
}

\author{
Mourad Makaci, Paul J. Reaidy, Karine Evrard Samuel, Valérie
}

Botta-Genoulaz, Thibaud Monteiro

\section{To cite this version:}

Mourad Makaci, Paul J. Reaidy, Karine Evrard Samuel, Valérie Botta-Genoulaz, Thibaud Monteiro. Pooled warehouse management: An empirical study. Computers \& Industrial Engineering, 2017, 112, pp.526-536. 10.1016/j.cie.2017.03.005 . hal-01531304

\section{HAL Id: hal-01531304 https://hal.science/hal-01531304}

Submitted on 4 Feb 2020

HAL is a multi-disciplinary open access archive for the deposit and dissemination of scientific research documents, whether they are published or not. The documents may come from teaching and research institutions in France or abroad, or from public or private research centers.
L'archive ouverte pluridisciplinaire HAL, est destinée au dépôt et à la diffusion de documents scientifiques de niveau recherche, publiés ou non, émanant des établissements d'enseignement et de recherche français ou étrangers, des laboratoires publics ou privés. 
doi: $10.1016 /$ j.cie.2017.03.005

\title{
POOLED WAREHOUSE MANAGEMENT: AN EMPIRICAL STUDY
}

\author{
Mourad MAKACI ${ }^{1, *}$, Paul REAIDY ${ }^{2}$, Karine EVRARD SAMUEL ${ }^{3}$, Valérie BOTTA- \\ GENOULAZ $^{4}$, Thibaud MONTEIRO ${ }^{5}$ \\ ${ }^{1,2,3}$ Université Grenoble Alpes, \\ * Groupe Sup Co de La Rochelle \\ CNRS, CERAG, F-38040, Grenoble \\ mourad.makaci@univ-grenoble-alpes.fr, paul.reaidy@univ-grenoble-alpes.fr \\ karine.samuel@grenoble-inp.fr \\ ${ }^{4,5}$ Université de Lyon, INSA-Lyon, DISP EA4570, \\ 69621 Villeurbanne, France \\ valerie.botta@insa-lyon.fr, thibaud.monteiro@insa-lyon.fr
}

\section{a b s t r a c t}

Today, pooled warehouse presents a major issue for supply chain actors. Managing such structures establishes a more complex and little known actions system. In this paper, we provide the main specificities of a pooled warehouse examined from the perspectives of both a literature review and an exploratory qualitative study built on seven cases in France. This study is based on semi-structured interviews with 22 companies managing projects in the field of pooled warehouses. From this qualitative analysis, we distinguish the main characteristics of pooled warehouses, such as compatibility and partner maturity, shared Vendor Managed Inventory, and collaborative management. In addition, we identify new key performance indicators, uncertainty sources and risks of pooled warehouses. This work helps define pooled warehouse concept and brings practitioners a better understanding of how it can be managed. Furthermore, it allows researchers to develop new models of optimization considering the pooling context. 


\section{Introduction}

In the context of a global economy characterized by increasing competition, companies try to improve their service level by intensifying means of distribution implementation (warehouses, transportation means). Moreover, environmental requirements in terms of $\mathrm{CO}_{2}$ emissions reduction, limitation due to land taxes, logistics costs and retailers' requirements (increased delivery frequency, decreased inventory levels) have obliged supply chain actors to revise their distribution strategies (warehousing and transport). These evolutions engender reflections on the development of new collaboration strategies in order to create more synergies between supply chain actors. Several studies have shown that logistics pooling is one of the collaborative approaches which allows reducing costs and meeting both customer and environmental requirements (Pan, Ballot, \& Fontane, 2013; Moutaoukil, Derrouiche, \& Neubert, 2012). According to Pan et al., (2013) logistics pooling involves sharing physical resources (warehouse, platforms, trucks), and organizations (logistics schemes), but also data necessary for managers to improve economic performance and supply chain environmental impact. Logistics pooling is defined as "pooling of logistics resources, organized by several actors, to group their flows to a single destination via transport and warehousing" (ECR France, 2013). Logistics pooling concerns pooled warehouse and transport pooling. Transport pooling has been largely studied, but pooled warehouse less so. Here, we are only interested in the pooled warehouse concept. Pooled warehouse can be defined as a warehouse shared logistically between several actors (manufacturers, logistics providers and distribution companies) in order to share physical spaces, resources and logistics information to improve the global performance of the overall distribution process (Makaci, Reaidy, Samuel, Botta-Genoulaz, \& Monteiro, 2015). This concept is relatively recent for companies, characterized by collaboration between actors and modifications of warehouse management in terms of organization, decision sharing and information sharing. The management of a Pooled Warehouse (PW) is considered as complex and dynamic (Reaidy, Gunasekaran, \& Spalanzani, 2015). It is subject to uncertainties and constraints related to the operations of the warehouse such as demand variation, the departure and arrival of new partners, distribution company pressure, and operations rules. However, pooled warehouse decisions are not made unilaterally. They take into consideration all pooled warehouse actors. Thus, Gonzalez and Morana (2014) stress the importance of developing new key performance indicators (KPI) for logistics pooling in order to improve decision making processes in a horizontal collaboration context. Likewise, the presence of several partners in pooled warehouse creates a dynamic environment which implies good coordination between partners. For these reasons, it is necessary to study more deeply the pooled warehouse concept by taking into consideration other management aspects such as collaborative and operational management of pooled warehouses (Makaci et al., 2015). Our research work aims to answer the following questions: "What are the specificities of a PW?" and "What are the uncertainty sources, risks, and new KPI of a PW?" We decided to explore these questions in agreement with the previous cited references. To do so, we conducted an exploratory study based on semi-structured interviews, which allows characterization of pooled warehouse. 
The remainder of the paper is organized as follows. In section 2, we study the concept of collaborative logistics and pooled warehouse in order to define pooled warehouse and its main processes. The research methodology based on semi-structured interviews is presented in section 3. Section 4 is dedicated to the results of our exploratory study concerning motivations to set up a pooled warehouse, pooled warehouse specificities, risks and uncertainty. The last section presents a discussion of the results and future research perspectives.

\section{Collaborative logistics and pooled warehouse}

This section briefly reviews some concepts and collaborative mechanisms to be applied in the pooled warehouse context. They are intended to enable a better understanding of the pooled warehouse concept.

\subsection{Collaborative logistics}

Collaborative logistics is a set of interactions between several supply chain actors to achieve the goals set for sharing resources, decisions, risks and benefits. Establishing an effective logistic collaboration can be vertical, horizontal, or lateral. Lambert et al. (1996) define vertical collaboration in logistics partnerships as "the process of working together among independent firms (two or more companies) along a supply chain in delivering products to end-customers for the basic purpose of optimizing longrange profit for all chain members and creating a competitive advantage". Cruijssen et al. (2007) define horizontal collaboration as "active collaboration between two or more firms that operate on the same level of the supply chain and perform a comparable logistics function on the landside". According to Simatupang and Sridharan (2002) "A lateral collaboration aims to gain more flexibility by combining and sharing capabilities in both vertical and horizontal manners". As stated earlier, previous research on collaboration logistics focuses mainly on the development of key factors of success and the ways to implement them. Audy, Lehoux, D’Amours, \& Rönnqvist (2012) develop five coordination mechanisms to implement the collaboration between supply chain actors to ensure information sharing, the coordination of logistics activities, and benefits sharing. The collaboration of the various supply chain actors allows making a profit via resource pooling, and sharing the strengths and capabilities of the different firms (Bartlett and Ghoshal, 2004) Implementation of collaborative logistics requires the presence of a third party to ensure transparency and to develop a reliable climate. Partnering with a third-party logistics provider (3PL) can lead to better performance in warehousing operations (Stank et al., 2001; Sinkovics and Roath, 2004). The majority of collaborative logistic warehouses are piloted by logistic service providers; a subject explored in many studies and having a strong presence in the literature. For example, Gunnar (2006) shows the interest and the role of 3PL in the management of this collaboration. Hingley et al. (2011) also show the interest of a 4PL presence to improve collaborative management. 


\subsection{Logistics pooling}

Logistics pooling is considered a form of logistics collaboration between several actors, allowing development of synergies between logistics actors to improve their performance (Moutaoukil et al., 2012). It involves sharing physical resources (warehouses, platforms, trucks), and organizations (logistics schemes), but also data necessary for managers to improve economic performance and supply chain environmental impact (Pan et al., 2013). According to ECR France (2013), logistics pooling is defined as "pooling of logistics resources, organized by several actors, to group their flows to a single destination via transport and warehousing”. Pooley and Stenger (1992) propose several forms of logistics pooling, such as pooled warehouse, platform pooling and transport pooling. The research developed in logistics pooling predominantly focuses on transport pooling and inventory pooling and less on pooled warehouse. For example, Ballot and Fontane (2010) show that transport pooling allows reducing $\mathrm{CO}_{2}$ emissions by $25 \%$. Li et al. (2014) demonstrate that the performance of collaborative planning for a logistics hub is superior to that resulting from decisions taken separately by suppliers and manufacturers. Wang and Yue (2015) develop a decision making model to determine the number of companies in a coalition that can share the storage cost of spare units. Kim and Benjaafar (2002) examine the benefits of inventory pooling in systems with finite capacity. Finally, Wanke and Saliby (2009) develop a framework for deciding whether and how inventories should be pooled.

\subsection{Pooled warehouse}

The warehouse is considered a major component of a supply chain. It allows strengthening product consolidation to reduce costs by means of economies of scale (Bartholdi III \& Hackman, 2010). According to Higginson and Bookbinder (2005), a warehouse is a place where products are stored during a long period. Hence, these authors define the logistics platform (hub or cross-docking) as a place of goods reception and forwarding in a very short time, the main objective of which is to redirect flows towards another destination. Several research studies have been developed on warehouse management. Gu, Goetschalckx, \& McGinnis (2007) establish a complete literature review on warehouse operation management including storage, order picking, handling, receiving and shipping. Berg \& Zijm (1999) propose a typology of warehouse management problems. Shiau \& Lee (2010) develop a hybrid algorithm to combine the operations of picking and packaging through a specific picking sequence. Another strand of research tries to implement production solutions. For example, Chen et al. (2013) introduce the integration of lean production and radiofrequency identification (RFID) as a technology to improve the efficiency of warehouse management. Other researchers (Gu, Goetschalckx, \& McGinnis, 2010; Gong \& Koster, 2011) focus on warehouse design and operations but do not integrate the pooling concept.

Several studies emphasize the role of pooled warehouse in transport. Plögera, Haasisa, \& Siestrupc (2008) consider it as a strategy to reduce costs and to use resources effectively to meet customer demand. Tuzkaya \& Önüt (2009) develop a linear programming model to optimize logistics networks (warehouse and transport) between suppliers and plants in order to maximize the profit of all members. 
Franklin \& Spinler (2011) consider that PW implementation improves performance thus reducing risks, and improves the eco-efficiency of logistics systems. The research developed in logistics pooling largely focuses on the pooling of transportation means. For example, Ballot \& Fontane (2010) show that transport pooling allows reducing $\mathrm{CO}_{2}$ emissions by 25\%. Wang \& Yue (2015) develop a decisionmaking model to determine the number of companies from a coalition to share the storage cost of such spare units.

The pooled warehouse concept has led to several initiatives that largely reflect efforts by industry trade associations (e.g., ECR France). However, little academic work has investigated, through empirical study, the internal operation of pooled warehouses (specificities, key performance indicators, uncertainty sources and risks, etc.). To our knowledge, warehouse management does not take into consideration the pooling concept (Camman, Monnet, Guieu, \& Livolsi, 2013; Makaci et al., 2015). To fill this gap, we apply the pooling concept to the warehouse context in order to explain and identify the key processes and actors of pooled warehouse. The context of PW can be modeled as follows (Figure 1):

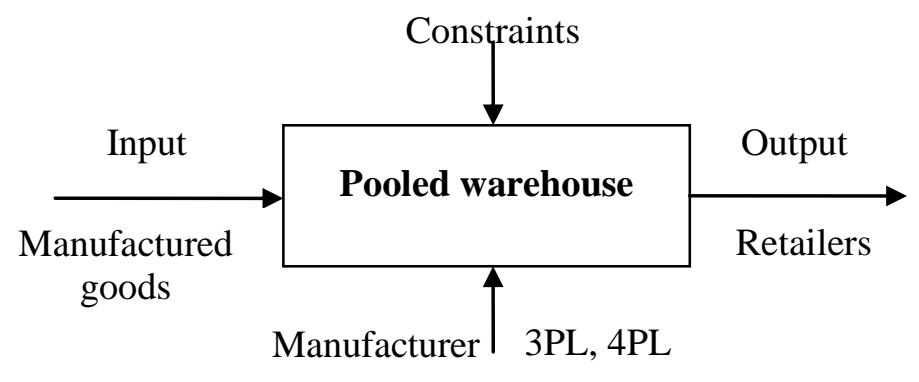

Figure 1: Pooled warehouse context

The "input" of a PW includes different manufacturers' products. The activity inside a PW consists of operations management, such as storage, order picking or handling, and receiving. The "output" concerns shipping processed goods to retailers, which can be delivered via pooled transport.

To understand the main processes of a PW, we propose a cartography (Figure 2). It illustrates three processes: the first one consists of a key operational process, which includes several sub-processes starting from the reception of the pallets of various partners to the delivery in shared trucks through pooled picking and loading in the same dock. The second process is the control process characterized by collaboration of all the actors (manufacturers, 3PL, 4PL, and retailers) for the management of the PW. The last process concerns support processes, which represent the internal activity that ensures smooth warehouse operations. This process includes management of human resources, material, information systems, methods, etc. 
Figure 2 : Pooled warehouse cartography

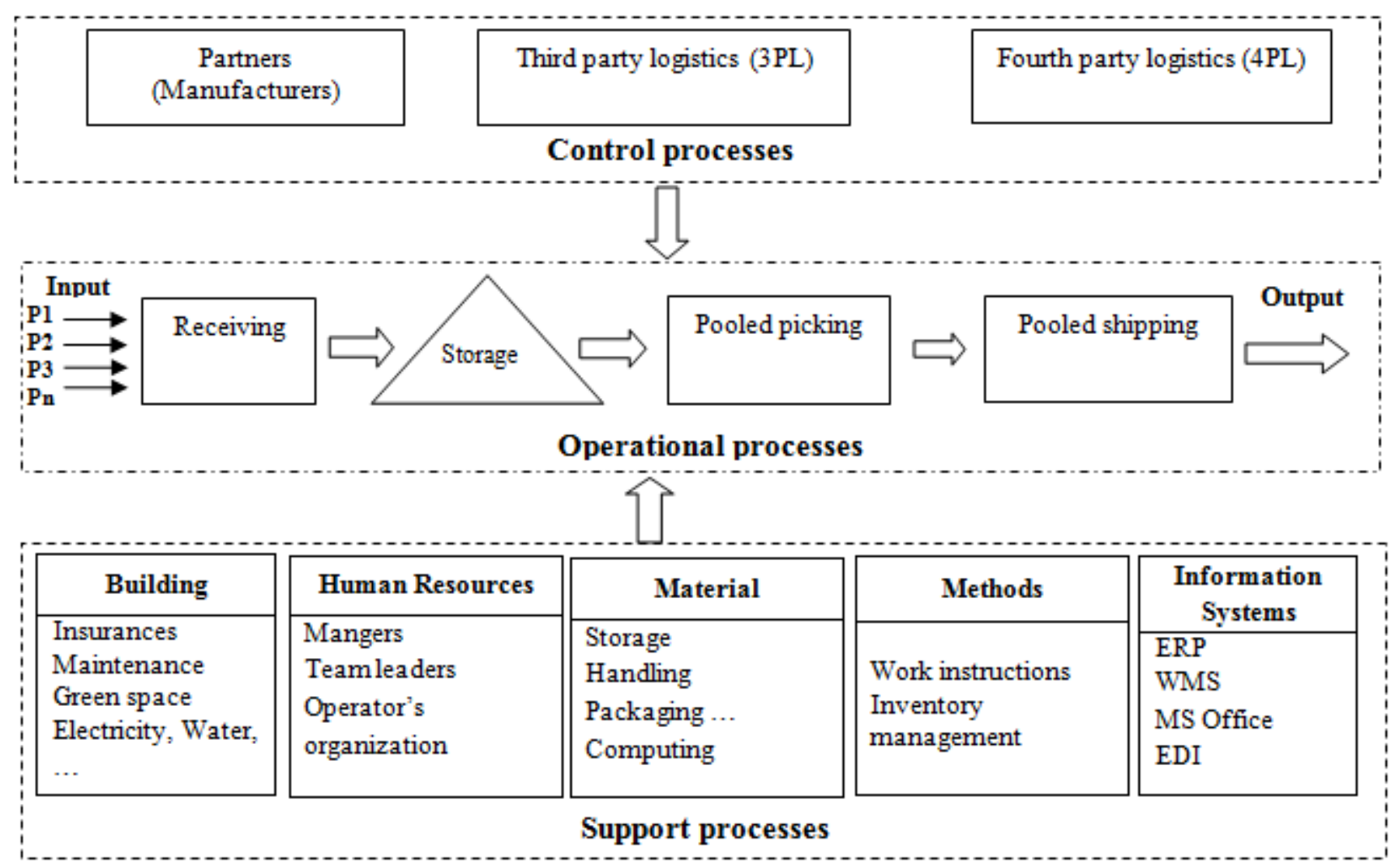

Before studying the operation of a PW, it is useful to characterize it. To achieve that, we identify several specificities using a qualitative approach complemented by a literature review. In the next section, we explain our main approach.

\section{Methodology}

The aim of this research is to understand the operation and management of a pooled warehouse. This issue justifies the use of an exploratory study method on multiple case studies in order to uncover areas for research and theory development (Rowley, 2002). Näslund (2002) considers that supply chain problems are often disordered and this justifies the choice of a qualitative approach allowing analysis in order to understand operations within supply chains. Qualitative research is the most convenient way to produce knowledge, especially when a gap between theory and practice exists in a persistent way in management sciences (Van de Ven \& Johnson, 2006). We used a qualitative method with an inductive approach to generate plentiful and diverse information and to perform a hybrid exploration (Eisenhardt, 1989). Research using the case-study method is employed to examine a contemporary phenomenon in its real-life context. Yin (1994) defines a case study as "an empirical enquiry that (1) investigates a contemporary phenomenon within its real-life context, especially when (2) the boundaries between phenomenon and context are not clearly evident". Yin (2003) describes three types of case studies: exploratory, explanatory and descriptive, indicating that all three are valid approaches. Exploratory research is appropriate here as very little is revealed in the academic literature about the pooled 
warehouse phenomenon. According to Yin (2008) there are three reasons why a case study research methodology is appropriate for our study. First, when "how" and "why" questions are investigated, a case study approach provides a description of linkages between events, rather than their frequencies or occurrence. Our study is an exploratory one, developing an understanding of how pooled warehouse is implemented and what its features are. Second, a case study approach is preferred when a real-world event is examined. Currently, many companies are actively engaged in implementing pooled warehouses. Several authors (Chakravorty, Hales, \& Herbert, 2008) insist on the necessity of realworld based research in order to help practicing managers stay competitive and to improve operations. Third, a case study approach is appropriate because this approach uses multiple sources of evidence, such as documents, archival records, interviews, and direct observation. For this, we opted for a multiple case study approach to augment external validity and help guard against observer bias. Each case was selected so that it predicts similar results (a literal replication) (Voss, Tsikriktsis, \& Frohlich, 2002).

This research is conducted over seven cases of French pooled warehouses performing in the consumer goods sector, initiated by manufacturers or by third party logistics providers. In fact, the manufacturer starts PW to satisfy wholesaler requirements by increasing the frequency of deliveries and by reducing stocks. However, a third party logistics provider can initiate the pooled warehouse in order to provide a service to the manufacturer with minimum cost. This can be achieved through the pooled warehouse that allows transport characterized by an increased delivery frequency. In fact, the warehouse has become a differentiation strategy for some third party logistics providers. In France, these cases are the most representative, in the sense that they collaborate between the different pooled warehouse actors. Table 1 provides a brief description of the different case properties.

The interviews (face-to-face or by phone) lasted roughly one hour. We guaranteed the anonymity of participants whose positions include supply chain manager, VMI director, logistics director, sales manager, operations director, and expert consultants in logistics pooling. All of the interviews were entirely recorded and transcribed. A total of 27 interviews for seven cases were conducted over a period of nine months. Interviewing 23 firm managers and four expert consultants allowed us to explore how the operation and management of pooled warehouse varies in different contexts. These cases were selected since they are considered as representative examples of pooled warehouse. Specifically, they show what kind of pooled warehouse can exist, how to manage PW, and how to ensure transparency between actors. 
Table 1: Pooled warehouse properties

\begin{tabular}{|c|c|c|c|c|c|}
\hline $\begin{array}{l}\text { Cases } \\
\text { (Pools) }\end{array}$ & Pooled warehouses & $\begin{array}{c}\text { Manufacturer } \\
\text { size }\end{array}$ & $\begin{array}{c}\text { Warehouse } \\
\text { area }\end{array}$ & $\begin{array}{c}\text { Product } \\
\text { type }\end{array}$ & $\begin{array}{c}\text { Competition } \\
\text { between } \\
\text { manufacturers } \\
\end{array}$ \\
\hline 1 & $\begin{array}{c}\text { Pooled warehouse } \\
\text { between seven } \\
\text { manufacturers }\end{array}$ & $\begin{array}{l}\text { Large } \\
\text { Medium } \\
\text { Small }\end{array}$ & $100000 \mathrm{~m}^{2}$ & Grocery & Yes \\
\hline 2 & $\begin{array}{l}\text { Pooled warehouse } \\
\text { between four } \\
\text { manufacturers }\end{array}$ & $\begin{array}{c}\text { Large } \\
\text { Medium }\end{array}$ & $80000 \mathrm{~m}^{2}$ & Grocery & Yes \\
\hline 3 & $\begin{array}{l}\text { Pooled warehouse } \\
\text { between two } \\
\text { manufacturers }\end{array}$ & $\begin{array}{c}\text { Large } \\
\text { Medium }\end{array}$ & $12000 \mathrm{~m}^{2}$ & Grocery & No \\
\hline 4 & $\begin{array}{l}\text { Pooled warehouse } \\
\text { between five } \\
\text { manufacturers }\end{array}$ & Large & $70000 \mathrm{~m}^{2}$ & Cosmetics & No \\
\hline 5 & $\begin{array}{c}\text { Pooled warehouse } \\
\text { between fifteen } \\
\text { manufacturers }\end{array}$ & $\begin{array}{l}\text { Medium } \\
\text { Small }\end{array}$ & $26000 \mathrm{~m}^{2}$ & Grocery & No \\
\hline 6 & $\begin{array}{c}\text { Pooled warehouse } \\
\text { between sixteen } \\
\text { manufacturers }\end{array}$ & $\begin{array}{l}\text { Medium } \\
\text { Small }\end{array}$ & $80000 \mathrm{~m}^{3}$ & $\begin{array}{l}\text { Frozen } \\
\text { products }\end{array}$ & No \\
\hline 7 & $\begin{array}{c}\text { Pooled warehouse } \\
\text { between fifteen } \\
\text { manufacturers }\end{array}$ & $\begin{array}{l}\text { Medium } \\
\text { Small }\end{array}$ & $400000 \mathrm{~m}^{2}$ & Grocery & No \\
\hline
\end{tabular}

The interviews enabled us to compare different pooled warehouse configurations, their functioning, as well as the individual perceptions of the importance given to economic and environmental issues. We triangulated the information gathered from the interviews with secondary data, such as professional workshops organized on the same thematic, in order to get a more accurate view of this type of collaboration. As indicated in Table 1, we have not interviewed all manufacturers because of availability and confidentiality issues.

Here, manufacturer size is based on the number of effective full-time employees (European Commission, 2015) and are separated into three categories; small (1-50), medium (50-250), and large $(250+)$. In our case, the French pooled warehouses are characterized by a horizontal collaboration (between the manufacturers to deliver to the same customers). However, to our knowledge, vertical collaboration (between manufacturer and wholesaler) is not developed.

Table 1 shows that the pooled warehouse is of particular interest for any type of enterprise, whether it is small, medium or large. For small and medium enterprises, the advantage of adopting such an approach is to reduce their logistic costs by sharing pooled warehouse and transport pooling resources. 
In contrast, large enterprises are interested in pooled warehouses when they have a smaller market share; hence they adopt pooling in order to optimize their storage and transportation. Table 2 provides a summary of the properties regarding the seven cases and interviews.

Table 2: List of PW case studies and interviews

\begin{tabular}{|c|c|c|c|c|}
\hline $\begin{array}{l}\text { Cases } \\
\text { (Pools) }\end{array}$ & $\begin{array}{c}\text { Pooled } \\
\text { warehouse }\end{array}$ & $\begin{array}{c}\text { Initiated } \\
\text { by }\end{array}$ & Interviews & Interviewees \\
\hline 1 & $\begin{array}{l}\text { PW between } \\
\text { seven } \\
\text { manufacturers }\end{array}$ & Manufacturers & $\begin{array}{l}\text { - } 1 \text { Third party logistics } \\
\text { provider } \\
\text { - } 1 \text { Fourth party logistics } \\
\text { provider } \\
\text { - } 3 \text { Manufacturers } \\
\text { - } 1 \text { Expert consultant }\end{array}$ & $\begin{array}{l}\text { - Manager Shared VMI } \\
\text { - Logistics director } \\
\text { - Operations director } \\
\text { - Sales manager } \\
\text { - Logistics manager }\end{array}$ \\
\hline 2 & $\begin{array}{l}\text { PW between } \\
\text { four } \\
\text { manufacturers }\end{array}$ & Manufacturers & $\begin{array}{l}\text { - } 1 \text { Third party logistics } \\
\text { provider } \\
\text { - } 1 \text { Fourth party logistics } \\
\text { provider } \\
\text { - } 3 \text { Manufacturers }\end{array}$ & $\begin{array}{l}\text { - Logistics manager } \\
\text { - Operations director } \\
\text { - Logistics director }\end{array}$ \\
\hline 3 & $\begin{array}{l}\text { PW between two } \\
\text { manufacturers }\end{array}$ & Manufacturers & $\begin{array}{l}\text { - } 2 \text { Manufacturers } \\
\text { - } 1 \text { Third party logistics } \\
\text { provider }\end{array}$ & $\begin{array}{l}\text { - Logistics director } \\
\text { - Supply chain director }\end{array}$ \\
\hline 4 & $\begin{array}{l}\text { PW between five } \\
\text { manufacturers }\end{array}$ & Manufacturers & $\begin{array}{l}\text { - } 1 \text { Third party logistics } \\
\text { provider } \\
\text { - } 1 \text { Fourth party logistics } \\
\text { provider } \\
\text { - } 2 \text { Manufacturers } \\
\text { - } 1 \text { Expert consultant }\end{array}$ & $\begin{array}{l}\text { - Logistics manager } \\
\text { - Supply chain director } \\
\text { - Supply chain manager }\end{array}$ \\
\hline 5 & $\begin{array}{l}\text { PW between ten } \\
\text { manufacturers }\end{array}$ & Manufacturers & $\begin{array}{l}\text { - } 1 \text { Third party logistics } \\
\text { provider } \\
\text { - } 1 \text { Manufacturer }\end{array}$ & $\begin{array}{l}\text { - Logistics director } \\
\text { - Supply chain manager }\end{array}$ \\
\hline 6 & $\begin{array}{l}\text { PW between } \\
\text { sixteen } \\
\text { manufacturers } \\
\text { (SMEs) }\end{array}$ & $3 \mathrm{PL}$ & $\begin{array}{l}\text { - } 1 \text { Third party logistics } \\
\text { provider } \\
\text { - } 1 \text { Manufacturer } \\
\text { - } 1 \text { Expert consultant }\end{array}$ & $\begin{array}{l}\text { - Logistics director } \\
\text { - Logistics manager }\end{array}$ \\
\hline 7 & $\begin{array}{l}\text { PW between } \\
\text { fifteen } \\
\text { manufacturers }\end{array}$ & $3 \mathrm{PL}$ & $\begin{array}{l}\text { - } 1 \text { Third party logistics } \\
\text { provider } \\
\text { - } 1 \text { Manufacturer } \\
\text { - } 1 \text { Expert consultant }\end{array}$ & $\begin{array}{l}\text { - Operations logistics director } \\
\text { - Deputy Director-General }\end{array}$ \\
\hline
\end{tabular}




\section{Data collection method}

The data collection method employed in this research was semi-structured interviews using open-ended interview protocol (Easterby-Smith, Thorpe, \& Lowe, 2002). Interviews were conducted in French by two researchers and all were recorded in their entirety. The transcripts were translated into English by an expert translator in order to ensure accurate adjudication and consistent data quality. Finally, 27 interviews on the seven cases were realized, in which there were 16 individual interviews and 11 round table interviews (cf. Table 3).

Table 3: Summary of the exploratory study

\begin{tabular}{lccc}
\hline Channel position & $\begin{array}{c}\text { Number of interviewees } \\
\text { face-to-face or by phone }\end{array}$ & $\begin{array}{c}\text { Number of interviewees } \\
\text { in round tables }\end{array}$ & $\begin{array}{c}\text { Total } \\
\text { interviews }\end{array}$ \\
\hline Manufacturers & 6 & 7 & $\mathbf{1 3}$ \\
Third party logistics & 6 & 1 & $\mathbf{7}$ \\
Fourth party logistics & 2 & 1 & $\mathbf{3}$ \\
Expert consultants & 2 & 2 & $\mathbf{4}$ \\
Total interviews & $\mathbf{1 6}$ & $\mathbf{1 1}$ & $\mathbf{2 7}$ \\
\hline
\end{tabular}

To carry out this study, an interview guide was built from the literature review and improved by professional comments (see Appendix 1). This guide, organized in three chapters, employs open questions. The first chapter concerns the interest and the advantages of PWs and the key success factors in the implementation of PWs. The second chapter focuses on the operation and management of PWs. Finally, the last chapter concerns the specificities of pooled warehouses. The interviews (face-to-face or by phone) lasted roughly one hour each; we also included reports stemming from reflections during the round tables on the same theme. We promised participant anonymity.

Interview data were simultaneously transcribed and coded. Coding allows reducing the quantity of data and grouping it in a thematic way (Yin, 2003). The triangulation principle is fundamental in data collection and concerns the use of multiple data sources (Voss et al., 2002). In our context, these methods consist of interview data, direct observation, and analysis of reports written by professionals in pooled warehouse. Some visits to pooled warehouses were undertaken by a team rather than by a single member, in an attempt to have complementary insights and enhance confidence in the findings. The level of agreement between the coders was 74 per cent which is considered to be an acceptable reliability rate for this type of study (Neuendorf, 2002).

\section{Findings}

The interviews carried out allowed describing the seven cases being studied. Once the data was collected, we analyzed it and built tables with verbatim texts in different parts of the interview guide. These verbatim texts provide important information allowing the user to draw valid conclusions (Miles \& Huberman, 1994). In our first analysis step, we analyzed each separate case before seeking to combine cases in order to generalize the results (Eisenhardt, 1989). This allows deeply understanding the functioning of the pooled warehouses using cross-case analysis. Cross-case analysis is concerned 
with identifying patterns between organizations of different cases and aims to improve understanding and provide explanations. It helps reduce the quantity of data, and gathers it in a thematic way (Yin, 1994). A comparison was made between the different cases to validate the results by seeking explanations and causality between results. Cross-case analysis allowed us to build a matrix of results for all cases. It is also essential to improving the generalizability of findings from the cases. The approach was used to refine our analysis and to look for similarities and differences that can occur in all cases. Cross-case analysis increases the internal validity of the results through the use of multiple data sources. The findings were discussed with some managers.

In this paper, we are interested in studying (in a general way) major aspects related to a pooled warehouse, namely its specificities, key performance indicators, uncertainty sources and risks. In the following sections, we present the results of our study.

\subsection{Pooled warehouse specificities}

Key findings of the empirical studies are summarized below, based on managers' interviews and the literature review.

- Partner compatibility: the compatibility of partners concerns the compatibility of products, information systems, sharing of the same customers, as well as physical characteristics (volume, type and number of customers, number of references, and storage space). The presence of several partners (including competitors) creates management complexity within the shared storage arrangement, the allocation of storage space, order picking and shipping in shared trucks. "The more you multiply the number of manufacturers, the more you will be confronted with compatibility problems" (Case 1, Manufacturer 1). The physical characteristics of partner products, input and output flows, demand variation, promotions and seasonality phenomena, competition and pressure from major outlets are the main features of pooled warehouse. "This is a good solution to deal with increasing pressure on distributors to reduce their stocks and increased frequency of delivery" (Case 4, 4PL).

- Shared information: Information sharing in real-time allows improving reactivity to management constraints and complexity engendered by various logistics actors (Li \& Lin, 2006). Simatupang \& Sridharan (2002) consider information sharing as an essential element for successful collaboration between supply chain actors. Botta-Genoulaz \& Pellegrin (2010) propose a conceptual framework for analyzing information exchange practices that organizations implement or could implement with their supply chain partners. According to interviews, the collaboration between the actors can be multilateral or bilateral. Multilateral collaboration means a total implication of partners in warehouse management. The identification of technical specifications is essential (i.e. the kinds of information to be shared or not between pool members) to detail the implementation of data platforms managed by fourth party logistics providers (4PL) in order to facilitate information access for all pooled warehouse members. "The use of a collaborative informational platform, which is also pooled, is essential for facilitating the pooled warehouse management" (Case 4, 4PL). "It must 
be accessible to each partner, from his site, and respect the confidentiality of information which is not universally shared" (Case 4, 4PL). In bilateral collaboration, the third party logistics provider manages all warehousing operation flows, that is to say, the partners share nothing among themselves; each one has its own contract with the third party logistics provider. "Each manufacturer gets access to its data (confidentiality management in the tool), manages parameterization and remains responsible for order proposal in regards to its own conditions with the retailers" (3PL). "We do not share information among the partners; every partner has his own relationship with the third party logistics provider" (Case 5, 3PL).

- Shared VMI (Vendor Managed Inventory): VMI is considered a collaboration strategy between several supply chain actors with the aim of ensuring product availability at minimum cost; the retailer gives his stock control to his manufacturer (Michaelraj \& Shahabudeen, 2009). VMI allows reducing costs and inventory levels, and improves customer service (Dong \& Xu, 2002; Waller, Johnson, \& Davis, 1999). Shared VMI allows a dynamic allocation of quantities proposed by a manufacturer, depending on real needs (no fixed lot size). According to the interviewed managers, it is essential to manage a PW in VMI mode to facilitate communication between the partners, the administrators and their customers. Because a PW contains more than two partners, management becomes complicated if the PW does not work in VMI mode. "It has proved necessary to integrate a VMI service in this activity; the objective of which is to coordinate the proposal of orders to maximize the number of complete trucks and take into account all the parameters allowing to improve the service level" (Case 4, 3PL). "Allowing a dynamic allocation of quantities proposed by manufactures, depending on real needs" (Case 4, 3PL).

- Collaborative PW management: Collaborative PW management is explained by partners' implication in PW management and decision-making. Scheduled meetings between the pool members serve to analyze failures and propose improvements. For example, to integrate new manufacturers in the pool, the decision will be taken by all pool members. Collaborative management between partners requires good organization and effective management that answers to the constraints of all partners. Camarinha-Matos, Afsarmanesh, Galeano, \& Molina (2009) show that partner collaboration requires means, organizational capabilities and a capacity for data exchange between them. "Such a project could not be undertaken without the implication of all the actors (programmed meeting every two weeks)" (Case 2, 3PL). "We can have different processes according to the number of manufacturers who are pooled, management rules, complexity, and customers since we can have rules of order picking which can be specific to the customers. Do we have to change promotions first? Or the standard products first? What if we can mix the pallets of different manufacturers with one another?" (Case 1, Manufacturer 1).

- Partner Maturity: According to the interviewees, identifying "good" partners facilitates collaboration and management of the pool. Each pool has its own strategy in terms of partner selection: product compatibility, information systems compatibility, customer sharing, demand 
characteristics, and shared vision. This type of collaboration requires partner maturity. The latter is explained by the resources possessed by each partner such as human resources, skills and material resources. "The main risk is to start a project with a manufacturer who finally does not have the ability to convince internally, has no maturity to do it, and has no available resources to undertake this type of project" (Case 2, 3PL). Partner unreliability is a leading source of managerial complexity in collaboration (Chalos \& O’Connor, 2004).

- PW Operations Management: The presence of several manufacturers (including competitors) creates a dynamic within the shared storage arrangement, the allocation of storage space, order picking and shipping. According to Faber et al. (2002) warehouse management complexity is explained by the quantity and heterogeneity of handled products, the extent of overlap between them, the amount and type of technology, and characteristics of associated processes. We consider complexity of a pooled warehouse as much greater because activities are pooled, such as order picking and loading on pooled docks. This leads to dynamic resource planning such as programming product storage placement and harmonization of capacity planning. "The grouping allows synchronizing the flows of storing and handling within the warehouse, so that the picking operations of all manufacturers are simultaneously read and tidied up on the same loading dock" (Case 1, 3PL). "The picking is without any doubt under stronger constraints because typically, the manufacturers do not want to see their products on the same pallets as the products of other manufacturers" (Case 2, 4PL). "Allowing a dynamic allocation of quantities proposed by manufactures, depending on real needs (no fixed lot size)" (Case 4, 3PL).

This multiple case study also allowed us to identify the advantages of pooled warehouse. The main advantages of the implementation of a pooled warehouse are ensuring full warehouse load and enabling transport pooling. Warehouse full-load allows increasing permanent staff, reducing temporary employees, and reducing fixed and variable costs. In contrast, the presence of several manufacturers in the same warehouse generates complexity in its management. This complexity requires a high level of collaboration and information sharing between manufacturers, retailers and logistics providers. In addition, pooled warehouse facilitates transport pooling, which allows increasing shipping frequency, reducing transport costs, reducing $\mathrm{CO}_{2}$ emissions, and increasing the service level. We summarize these advantages below (Figure 3). 
Figure 3:The main advantages of pooled warehouse

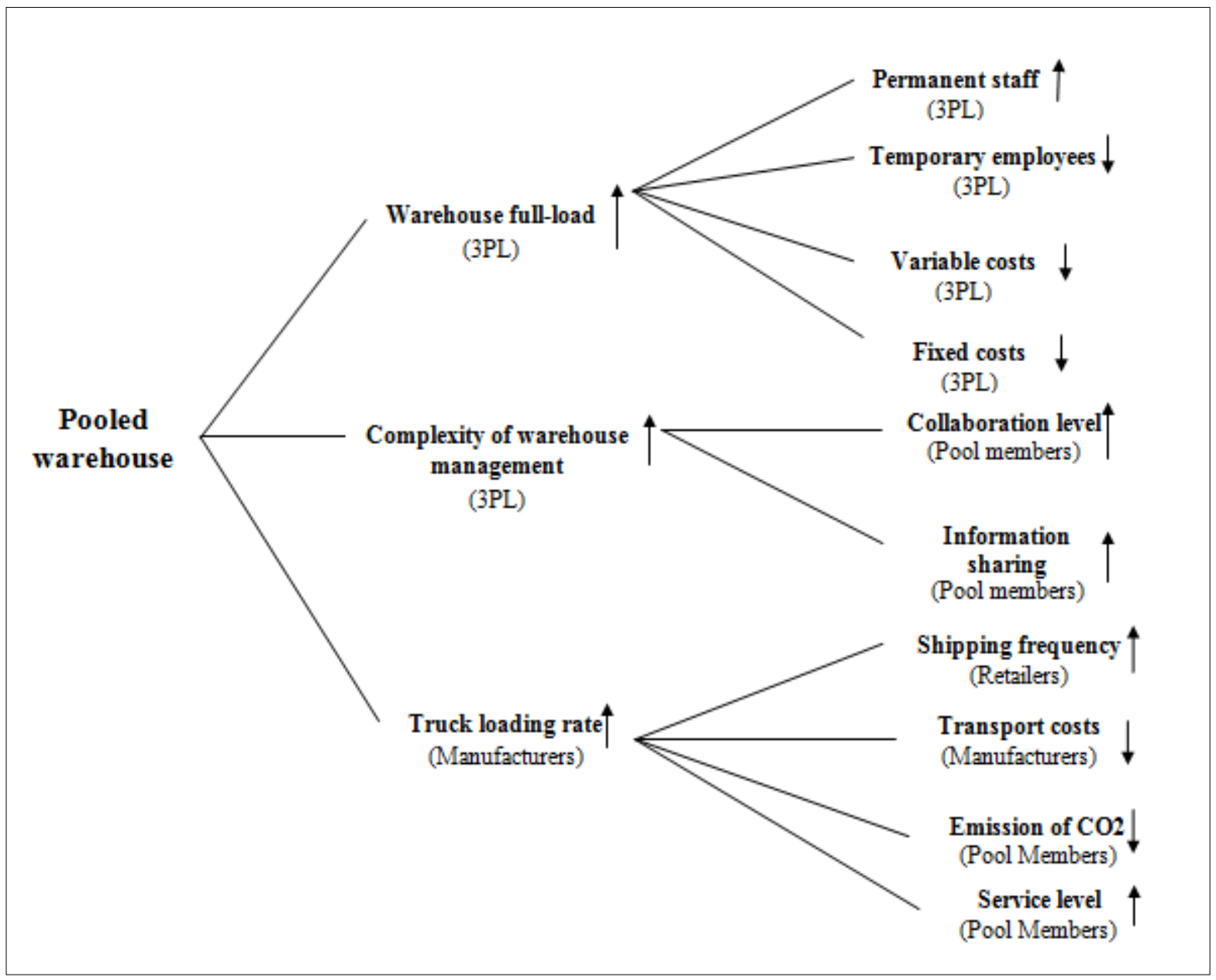

\subsection{Key performance indicators in pooled warehouse}

The main objective of any company is reducing logistics costs, as well as improving the services provided for its customers. Third party logistics providers (3PL) are considered as important supply chain actors. Pooled warehouses have become a recent collaborative practice that allows supply chain actors to reduce their costs. This practice creates a new challenge for a 3PL to insure close collaboration with their partners (manufacturers, distributors, retailers). It allows exchanging data and necessary information, thus enhancing collaborative decisions. Performance indicators help the managers in the decision-making process. For this purpose, we are also interested in studying the performance indicators of pooled warehouses calculated in the various pools. On the one hand, several works were developed on performance indicators at the level of warehouse management, for example, service level, warehouse fill-rate, delivery rate, and truck loading rate (Krauth, Moonen, Popova, \& Schut, 2005). On the other hand, few works integrate the pooling context with the exception of some works on transport pooling ( Gonzalez-Feliu \& Morana, 2014). 
Our literature review proposes some KPIs in the transport pooling context. It concerns the truck loading rate and CO2 emissions (Pan et al., 2013; Morana \& Gonzalez-Feliu, 2012). This exploratory study allowed us to identify new KPIs used in a pooled warehouse context. These indicators and their calculation formula are developed from the conducted interviews.

\section{Indicator for pooled warehouse}

$P W$ Fill rate $(\%)=\frac{\text { Total volume stored }}{\text { Total available volume }} * 100$

This indicator calculates the occupancy rate of pooled warehouse.

$P W$ Fill rate per manufacurer $(\%)=\frac{\text { Total volume per manufacturer }}{\text { Total available volume per manufacturer }} * 100$

This indicator calculates the occupancy rate of pooled warehouse per manufacturer.

\section{Indicator for transport pooling}

Truck loading rate $(\%)=\frac{\text { Load carried } * \text { number of } \mathrm{km} \text { travelled per load }}{\text { Truck load capacity } * \text { total number of } \mathrm{km} \text { travelled }} * 100$

This indicator is calculated only for pooled warehouse downstream between pooled warehouse and warehouse retailer (Gonzalez and Morana, 2014). It reflects the percentage of truck loading. Load carried: quantity transported (number of pallets transported);

Number of $\mathrm{km}$ travelled per load: the number of kilometers carried by the truck during the delivery, knowing that the truck is not empty;

Truck load capacity: the maximal capacity which a truck can carry;

Total number of $\mathrm{km}$ travelled: the number total of kilometers traveled by the truck during the delivery.

\section{Delivery pooling rate}

Delivery pooling rate $(\%)=\frac{\text { Number of deliveries pooled }}{\text { Total delivery number }} * 100$

This indicator reflects the percentage of pooled deliveries between the pooling warehouse and the retailer warehouse.

\section{Pooling benefits}

Pooling benefits $=$ logistics costs before pooling - logistics costs after pooling

Logistics costs before pooling $=\sum$ warehousing costs $+\sum$ transport costs

(Without pooling)

Logistics costs after pooling $=\sum$ warehousing costs $+\sum$ transport costs

(With pooling)

This indicator measures the gains of logistics pooling (warehouse and transport). 


\subsection{Uncertainty sources and risks of pooled warehouse}

In this exploratory study, we are also interested in identifying the uncertainty sources and risks for this type of collaboration. The interview analyses identified these uncertainty sources and risks. We classified them on two axes distributed in three levels (see Figure 4): the first one represents their effects on the decisions' levels (strategic, tactical and operational). The second represents the context: (1) upstream of the PW, includes the input which consists of the different manufacturers' products. (2) Inside the PW, we have the operations management, such as storage, order picking or handling, and receiving. (3) Downstream of the PW concerns shipping processed goods to retailers, which can be delivered through pooled transport (see Figure 3). This schema helps managers in their decision making process for the pooled warehouse, taking into consideration characteristics both outside and inside the PW.

Figure 4: Uncertainty sources and risks of pooled warehouse

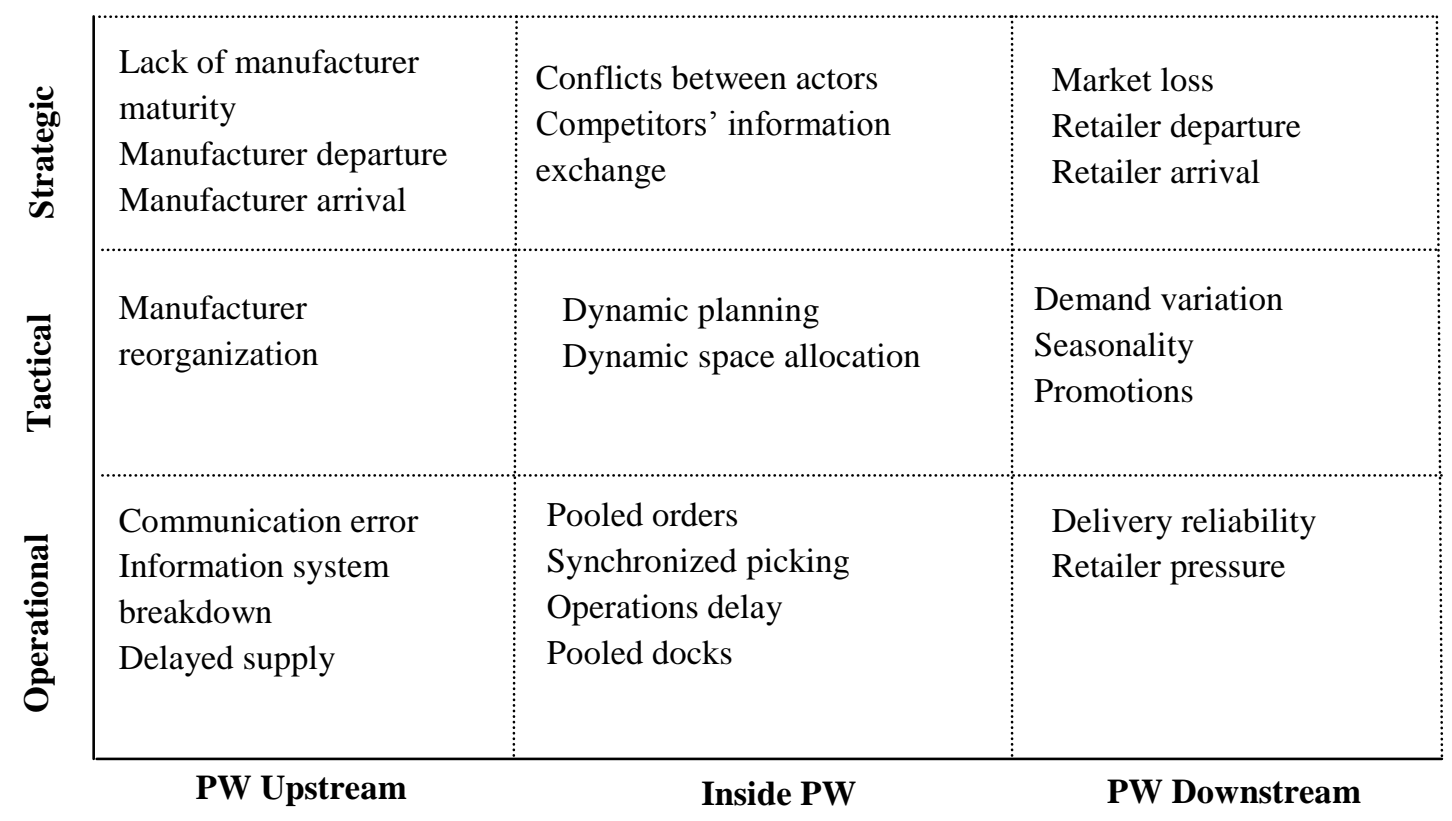

\section{Strategic level}

The uncertainty sources and risks of a PW at a strategic level are: the departure and arrival of new manufacturers and/or retailers. In PW upstream the arrival or departure of a manufacturer can create changes within the management of a PW. Furthermore, in PW downstream, if a retailer arrives or leaves the collaboration, this can create changes to both the PW management, and to management of transport pooling. "It is possible that one manufacturer faces commercial problems with his retailer, at this moment the retailer decides that he will stop working with the manufacturer and very simply the manufacturer is going to pull out of the pooled warehouse" (Case 1, Manufacturer 1). In inside PW, it can also create conflicts between partners if information exchange between competitors is not protected. "If the rules of the game are not clear, multiple conflicts can be created, introducing multiple debates" (Case 3, Manufacturer 1). If a manufacturer faces a market loss or is not sufficiently 
mature, it can negatively impact PW management. "The main risk is to start a project with a manufacturer who finally does not have the ability to convince internally, has no maturity to do it, and has no available resources to undertake this type of project" (Case 2, 3PL).

\section{Tactical level}

The main uncertainty sources and risks at the tactical level are demand variation, mainly generated by seasonality and promotions. Demand variation can generate more complexity in PW downstream management and a lack of medium-term visibility. It also requires dynamic delivery planning of PW upstream, PW supplying, and dynamic space allocation for each manufacturer. In addition, this may cause changes in a manufacturer's organization in inside PW. "So, the reorganization of a manufacturer can change further after his integration in the PW" (Case 1, Manufacturer 2).

\section{$>$ Operational level}

Supply delays and communication errors in PW downstream between retailers and manufacturers (such as stock levels and information systems problems) negatively influence the realization of warehousing operations. So, retailer pressure increases complexity for manufacturers and logistics providers. Uncertainty sources in PW upstream are communication errors between a manufacturer and the 3PL, information system breakdown and delayed supply. Moreover, uncertainty sources and risks may exist in inside the PW, such as preparation of pooled orders, synchronized picking and pooled docks. "The loading is done on a dock that is specifically dedicated to the pooled flow" (Case 1, Manufacturer 3). "The pooling allows synchronizing the storage and handling flows, so that picking for industrial pallets are prepared simultaneously and handled on the same dock"(Case 4, 3PL).

The PW is characterized by its management mode (participation of all actors, sharing decisions and knowledge), shared VMI, pooled order picking, and pooled docks. These specificities highlight the complexity of pooled warehouse management at strategic, tactical and operational levels. This type of collaboration requires a long-term partner commitment with the aim of developing new modes of organization, and adapted information systems to facilitate information sharing.

\section{Conclusion}

In this paper, we explain how pooled warehouse is managed, what its specificities are, new KPI, uncertainty sources and risks. We based our research on an exploratory study of multiple case studies. These specificities explain why pooled warehouse management has to incite close collaboration between actors. To date, research focusing on the warehouse context has not considered pooling constraints. These specificities allow better understanding of pooled warehouse operations and distinguish it from a simple warehouse.

The main result of our empirical study is the formulation of pooled warehouse specificities such as partner compatibility, collaborative management, partner maturity, shared information systems, shared VMI, and PW operations management. 
This paper may help practitioners in their decision-making processes when they intend to integrate or to set up a pooled warehouse in a supply chain. Moreover, this paper allows researchers to develop new approaches to pooled warehouse management by integrating the constraints and variables which are appropriate to pooling specificities.

The data set itself remains limited by the number of cases in France and by the time duration. Future research should expand the data set across different countries and over a longer period. Also, four aspects of warehouse management are developed generally, such as "pooled warehouse", "specifications of pooled warehouse", "key performance indicators", and "sources of uncertainties in PW". In future perspectives, we intend to examine deeply each specific part and investigate it comprehensively.

A direction for future research is the generalization of these results and testing in practice via pooled warehouse flow simulation by integrating these specificities. It is also possible to try to observe other variations of change and examine the resulting efficiency level of the pooled warehouse process.

\section{References}

Audy, J.-F., Lehoux, N., D’Amours, S., \& Rönnqvist, M. (2012). A framework for an efficient implementation of logistics collaborations. International Transactions in Operational Research, 19(5), 633-657.

Ballot, E., \& Fontane, F. (2010). Reducing transportation CO2 emissions through pooling of supply networks: perspectives from a case study in French retail chains. Production Planning \& Control, 21(6), 640-650.

Bartholdi III, J. J., \& Hackman, S. T. (2010). Warehouse \& distribution science: release 0.92. The Supply Chain and Logistics Institute, School of Industrial and Systems Engineering, Georgia Institute of Technology, Atlanta, GA, 30332.

Bartlett, C., \& Ghoshal, S. (2004). Managing across boundaries: the collaborative challenge. Text, Cases and Readings in Cross-Border Management, 403-502.

Berg, J. P. van den, \& Zijm, W. H. M. (1999). Models for warehouse management: Classification and examples. International Journal of Production Economics, 59(1-3), 519-528.

Botta-Genoulaz, V., \& Pellegrin, C. (2010). Information-Sharing Practices and their Impacts on Supply Chain Performance. Supply Chain Performance: Collaboration, Alignment and Coordination, 53-93.

Camarinha-Matos, L. M., Afsarmanesh, H., Galeano, N., \& Molina, A. (2009). Collaborative networked organizations - Concepts and practice in manufacturing enterprises. Computers \& Industrial Engineering, 57(1), 46-60.

Camman, C., Monnet, M., Guieu, G., \& Livolsi, L. (2013). Les stratégies d'acteurs dans la mutualisation logistique. Logistique \& Management, 21(3), 57-75.

Chakravorty, S. S., Hales, D. N., \& Herbert, J. I. (2008). How problem-solving really works. International Journal of Data Analysis Techniques and Strategies, 1(1), 44-59.

Chalos, P., \& O'Connor, N. G. (2004). Determinants of the use of various control mechanisms in US-Chinese joint ventures. Accounting, Organizations and Society, 29(7), 591-608.

Chanut, O., \& Paché, G. (2011). Supply networks in urban logistics-Which strategies for 3PL. In EMNet Conference (pp. 1-19). 
Chen, J. C., Cheng, C.-H., Huang, P. B., Wang, K.-J., Huang, C.-J., \& Ting, T.-C. (2013). Warehouse management with lean and RFID application: a case study. The International Journal of Advanced Manufacturing Technology, 69(1-4), 531-542.

Cruijssen, F., Dullaert, W., \& Fleuren, H. (2007). Horizontal Cooperation in Transport and Logistics: A Literature Review. Transportation Journal, 46(3), 22-39.

Dekker, R., Bloemhof, J., \& Mallidis, I. (2012). Operations Research for green logistics - An overview of aspects, issues, contributions and challenges. European Journal of Operational Research, 219(3), 671679.

Dong, Y., \& Xu, K. (2002). A supply chain model of vendor managed inventory. Transportation Research Part E: Logistics and Transportation Review, 38(2), 75-95.

Easterby-Smith, M., Thorpe, R., \& Lowe, A. (2002). Management research methods. London: Sage Publications Examinership-Friel Stafford, Available from Www. Liquidation. Ie.

ECR France. (2013). Collaborative logistics barometer.

Eisenhardt, K. M. (1989). Building Theories from Case Study Research. Academy of Management Review, 14(4), 532-550.

European Commission. (2015). What is an SME?, Enterprise and Industry, European Commission. (http://ec.europa.eu/enterprise/policies/sme/facts-figures-analysis/sme-definition/index_en.htm).

Faber, N., de Koster, R. (Marinus) B., \& van de Velde, S. L. (2002). Linking warehouse complexity to warehouse planning and control structure: an exploratory study of the use of warehouse management information systems. International Journal of Physical Distribution \& Logistics Management, 32(5), 381-395.

Franklin, R., \& Spinler, S. (2011). Shared Warehouses - Sharing Risks and Increasing Eco-efficiency. International Commerce Review, 10(1), 22-31.

Gong, Y., \& Koster, R. B. M. de. (2011). A review on stochastic models and analysis of warehouse operations. Logistics Research, 3(4), 191-205.

Gonzalez-Feliu, J., Peris-Pla, C., \& Rakotonarivo, D. (2010). Simulation and optimization methods for logistics pooling in the outbound supply chain (pp. 394-401). Presented at the Third International Conference on Value Chain Sustainability. "Towards a Sustainable Development and Corporate Social Responsibility Strategies in the 21st Century Global Market.

Gonzalez-Feliu, J., \& Morana, J. (2014). Assessing urban logistics pooling sustainability via a hierarchic dashboard from a group decision perspective. Sustainable Logistics. Emerald Group Publishing, series: Transport and Sustainability, (6), 113-135.

Gu, J., Goetschalckx, M., \& McGinnis, L. F. (2007). Research on warehouse operation: A comprehensive review. European Journal of Operational Research, 177(1), 1-21.

Gu, J., Goetschalckx, M., \& McGinnis, L. F. (2010). Research on warehouse design and performance evaluation: A comprehensive review. European Journal of Operational Research, 203(3), 539-549.

Gunasekaran, A., \& Ngai, E. W. (2004). Information systems in supply chain integration and management. European Journal of Operational Research, 159(2), 269-295.

Gunnar Stefansson. (2006). Collaborative logistics management and the role of third-party service providers. International Journal of Physical Distribution \& Logistics Management, 36(2), 76-92.

Heide, J. B., \& John, G. (1990). Alliances in Industrial Purchasing: The Determinants of Joint Action in BuyerSupplier Relationships. Journal of Marketing Research, 27(1), 24-36. 
Higginson, J. K., \& Bookbinder, J. H. (2005a). Distribution Centres in Supply Chain Operations. In A. Langevin \& D. Riopel (Eds.), Logistics Systems: Design and Optimization (pp. 67-91). Springer US.

Hingley, M., Lindgreen, A., Grant, D. B., \& Kane, C. (2011). Using fourth-party logistics management to improve horizontal collaboration among grocery retailers. Supply Chain Management: An International Journal, 16(5), 316-327.

Jennifer Rowley. (2002). Using case studies in research. Management Research News, 25(1), 16-27.

Kim, J.-S., \& Benjaafar, S. (2002). On the Benefits of Inventory-Pooling in Production-Inventory Systems. Manufacturing \& Service Operations Management, 4(1), 12-16.

Kohn, C., \& Brodin, M. H. (2008). Centralised distribution systems and the environment: how increased transport work can decrease the environmental impact of logistics. International Journal of Logistics: Research and Applications, 11(3), 229-245.

Krauth, E., Moonen, H., Popova, V., \& Schut, M. (2005). Performance indicators in logistics service provision and warehouse management-a literature review and framework. In Euroma International Conference (pp. 19-22).

Lambert, D. M., Emmelhainz, M. A., \& Gardner, J. T. (1996). Developing and implementing supply chain partnerships. The International Journal of Logistics Management, 7(2), 1-18.

Li, G., Lv, F., \& Guan, X. (2014). A Collaborative Scheduling Model for the Supply-Hub with Multiple Suppliers and Multiple Manufacturers. The Scientific World Journal, 2014, e894573.

Makaci, M., Reaidy, P., Samuel, K., Botta-Genoulaz, V., \& Monteiro, T. (2015). A typology for warehouse pooling: an exploratory study. In The 10th European Research Seminar on Logistcs and SCM (ERS 2015). Copenhagen, Danmark, 23 pages.

Michaelraj, L. A., \& Shahabudeen, P. (2009). Replenishment policies for sustainable business development in a continuous credit based vendor managed inventory distribution system. Computers \& Industrial Engineering, 56(1), 260-266.

Miles, M. B., \& Huberman, A. M. (1994). Qualitative data analysis: An expanded sourcebook. Sage.

Morana, J., Gonzalez-Feliu, J., \& Semet, F. (2014). Urban consolidation and logistics pooling. In Sustainable urban logistics: Concepts, methods and information systems (pp. 187-210). Springer.

Moutaoukil, A., Derrouiche, R., \& Neubert, G. (2012). Pooling Supply Chain: Literature Review of Collaborative Strategies. In L. M. Camarinha-Matos, L. Xu, \& H. Afsarmanesh (Eds.), Collaborative Networks in the Internet of Services (pp. 513-525). Springer Berlin Heidelberg.

Näslund, D. (2002). Logistics needs qualitative research-especially action research. International Journal of Physical Distribution \& Logistics Management, 32(5), 321-338.

Neuendorf, K. A. (2002). The content analysis guidebook. Sage.

Nynke Faber, René (Marinus) B.M. de Koster, \& Steef L. van de Velde. (2002). Linking warehouse complexity to warehouse planning and control structure: An exploratory study of the use of warehouse management information systems. International Journal of Physical Distribution \& Logistics Management, 32(5), 381-395.

Pan, S., Ballot, E., \& Fontane, F. (2013). The reduction of greenhouse gas emissions from freight transport by pooling supply chains. International Journal of Production Economics, 143(1), 86-94.

Pooley, J., and Stenger, A.J., 1992. "Modeling and Evaluating Shipment Consolidation in a Logistics System.” Journal of Business Logistics 13 (2): 153-174.

Plögera, M., Haasisa, H.-D., \& Siestrupc, G. (2008). Dynamic Warehouse Sharing in Supply Chains. A Software-Based Multi-Agent Coordination Approach (pp. 364-372). Retrieved from 
Reaidy, P. J., Gunasekaran, A., \& Spalanzani, A. (2015). Bottom-up approach based on Internet of Things for order fulfillment in a collaborative warehousing environment. International Journal of Production Economics, 159, 29-40.

Rowley, J. (2002). Using case studies in research. Management Research News, 25(1), 16-27.

Salmon, K. (2011). Pratiques de logistique collaborative: quelles opportunités pour les PME/ETI? Pôle interministériel de prospective et d'anticipation des mutations économiques (PIPAME), Ministère de l'Economie, des Finances et de l'Industrie. France.

Shiau, J.-Y., \& Lee, M.-C. (2010). A warehouse management system with sequential picking for multi-container deliveries. Computers \& Industrial Engineering, 58(3), 382-392.

Simatupang Togar M., \& Sridharan R. (2002). The Collaborative Supply Chain. The International Journal of Logistics Management, 13(1), 15-30.

Sinkovics, R. R., and Roath, A. S. (2004). Strategic Orientation, Capabilities, and Performance in Manufacturer-3PL Relationships. Journal of business Logistics, 25(2), 43-64.

Stank, T. P., Keller, S. B., and Daugherty, P. J. (2001). Supply Chain Collaboration and Logistical Service Performance. Journal of Business Logistics 22 (1): 29-48.

Tuzkaya, U. R., \& Önüt, S. (2009). A holonic approach based integration methodology for transportation and warehousing functions of the supply network. Computers \& Industrial Engineering, 56(2), 708-723.

Van de Ven, A. H., \& Johnson, P. E. (2006). Knowledge for theory and practice. Academy of Management Review, 31(4), 802-821.

Ven, A. H. V. D., \& Johnson, P. E. (2006). Knowledge for Theory and Practice. Academy of Management Review, 31(4), 802-821.

Voss, C., Tsikriktsis, N., \& Frohlich, M. (2002). Case research in operations management. International Journal of Operations \& Production Management, 22(2), 195-219.

Waller, M., Johnson, M. E., \& Davis, T. (1999). Vendor-managed inventory in the retail supply chain. Journal of Business Logistics, 20, 183-204.

Wang, W., \& Yue, S. (2015). An inventory pooling model for spare units of critical systems that serve multicompanies. Transportation Research Part E: Logistics and Transportation Review, 76, 34-44.

Wanke, P. F., \& Saliby, E. (2009). Consolidation effects: Whether and how inventories should be pooled. Transportation Research Part E: Logistics and Transportation Review, 45(5), 678-692.

Yin, R. (1994). Case study research: Design and methods . Beverly Hills. CA: Sage publishing.

Yin, R. K. (2003). Case study research design and methods third edition. Applied Social Research Methods Series, 5 .

Yin, R. K. (2008). Case Study Research: Design and Methods. SAGE Publications.

Zacharia, Z. G., Sanders, N. R., \& Nix, N. W. (2011). The Emerging Role of the Third-Party Logistics Provider (3PL) as an Orchestrator. Journal of Business Logistics, 32(1), 40-54.

Zeimpekis, V. (2011). Goods distribution management in city logistics environment: A systemic approach. Advances in Management and Applied Economics, 1(1), 151. 


\section{Appendix 1}

\section{Interview Guide}

1. You share the warehouse with other actors. Who initiated this pooled warehouse project? (ECR France, 2013)

2. Who are the actors in the pooled warehouse? Are they competing? (Cruijssen et al., 2007; Salmon, 2011)

3. In your opinion, what are the triggers of this initiative? (ECR France, 2013)

4. Could you describe this pooled warehouse? What are its characteristics?

5. Following the establishment of a pooled warehouse, what type of relationship exists? Have you developed one with the other actors? (Heide \& John, 1990; Hingley, Lindgreen, Grant, \& Kane, 2011)

6. What information do you share? (Morana, Gonzalez-Feliu, \& Semet, 2014; Gunasekaran \& Ngai, 2004)

What are the tools used commonly among actors?

7. Who manages the pooled warehouse? (Gunnar, 2006; Zacharia, Sanders, \& Nix, 2011)

8. If it is managed by a third party logistics provider, why should you trust it? (Chanut \& Paché, 2011)

9. Do you share the transport? (Pan et al., 2013)

10. In your opinion, is there a link between the transport pooling and the pooled warehouse? (Kohn \& Brodin, 2008; Gonzalez and Morana, 2014)

What are the KPI used? (Gonzalez and Morana, 2014)

Who set them?

Are they shared between actors?

11. Have you identified management constraints of a pooled warehouse? (Audy et al., 2012; Makaci et al., 2015)

12. How do you arbitrate the reception, storage and shipping between manufacturers? (Berg \& Zijm, 1999; Camarinha-Matos et al., 2009; Gu et al., 2007) 
13. Are there new processes that can be integrated into the pooling context? If yes, which ones? (Gu et al., 2007)

14. In your opinion, how is a pooled warehouse different from a non-pooled warehouse?

15. What are the specificities of a pooled warehouse? (Plögera et al., 2008)

16. Have you identified the uncertainty sources and risks of pooled warehouse? (Franklin \& Spinler, 2011; Zeimpekis, 2011)

At what level? 